\title{
Hydatid cyst: hepatitis B and D coinfection accelerating the course of the disease
}

\author{
Jessica Patel, ${ }^{1}$ Muzzammil Ali ${ }^{1,2}$
}

${ }^{1}$ Queen Elizabeth Hospital Birmingham, Birmingham, UK ${ }^{2}$ Heart of England NHS Foundation Trust, Birmingham, UK

\section{Correspondence to} Dr Muzzammil Ali, muzzammil.ali@nhs.net

Accepted 21 February 2017
CrossMark

To cite: Patel J, Ali M. BMJ Case Rep Published online: [please include Day Month Year] doi:10.1136/bcr-2017219569

\section{DESCRIPTION}

A Romanian man aged 31 years presented to the liver clinic with recurrent right upper quadrant pain. He had moved to the UK a few months prior to his first appointment. His background included chronic e-antigen-negative hepatitis B infection, Child-Pugh A liver cirrhosis with portal hypertension, and a known hydatid cyst for which he had two previous liver resections and 6 months of albendazole.

On further investigation, hydatid serology was confirmed, FibroScan score was 34 and blood tests revealed stable liver function tests, thrombocytopenia, latent syphilis and a hepatitis D coinfection. The latter accounted for his accelerated disease course. Ultrasonography showed a large complex cyst within the right lobe of the liver, splenomegaly and a previous cholecystectomy (figure 1). CT confirmed a viable hydatid cyst (figure 2 ). There were no extrahepatic manifestations of hydatid disease.

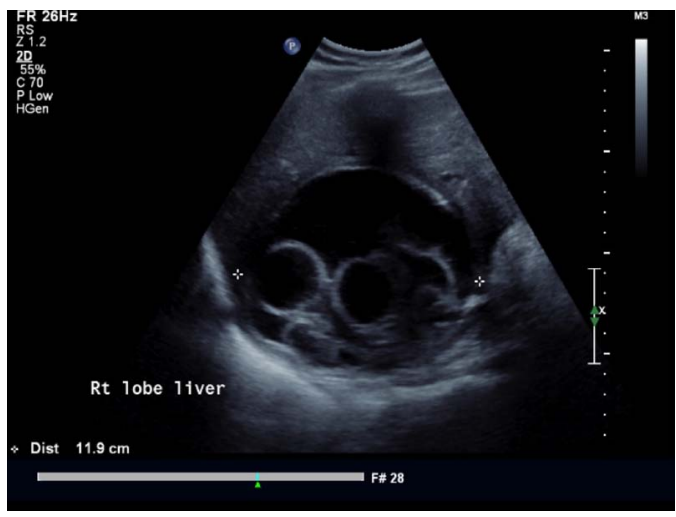

Figure 1 Ultrasound: fatty, coarse liver with a hydatid cyst in the right lobe measuring $12.2 \times 11.9 \times 13.9 \mathrm{~cm}$ with daughter cysts (septations).

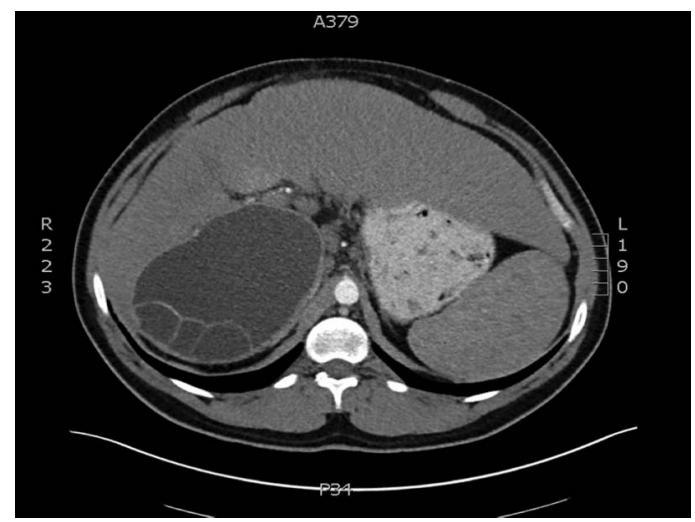

Figure 2 CT triple phase: large hydatid cyst with daughter cysts and calcification at the posterior aspect of the right liver.
Since his cirrhosis was well compensated, this allowed sufficient time to conduct a multidisciplinary team (MDT) meeting involving members of radiology, liver surgery, hepatology and national parasitology. Since surgical intervention is associated with a high risk of decompensation, highdose albendazole is potentially hepatotoxic, and medical management alone would have been suboptimal, a consensus was reached to try PAIR (puncture aspiration injection reaspiration) alongside lower-dose albendazole, entecavir and doxycycline. Unfortunately, a magnetic resonance cholangiopancreatography performed prior to PAIR showed biliary communication with the cyst (figures 3 and 4), a contraindication to performing PAIR. This made devising a subsequent management plan very difficult.

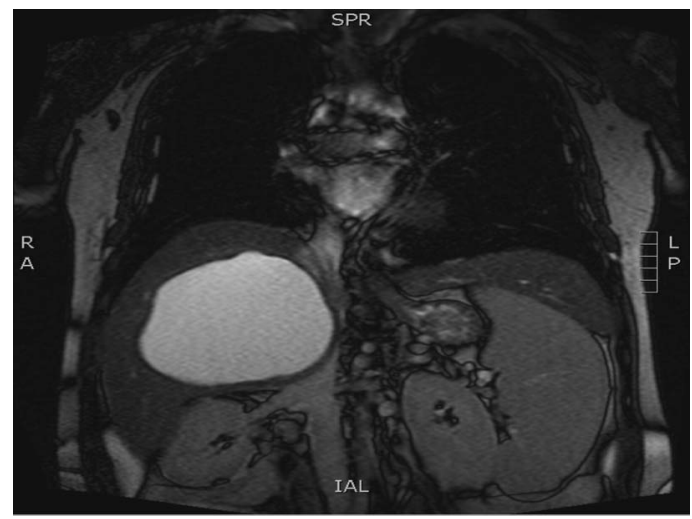

Figure 3 Magnetic resonance cholangiopancreatography: large right lobe hydatid cyst.

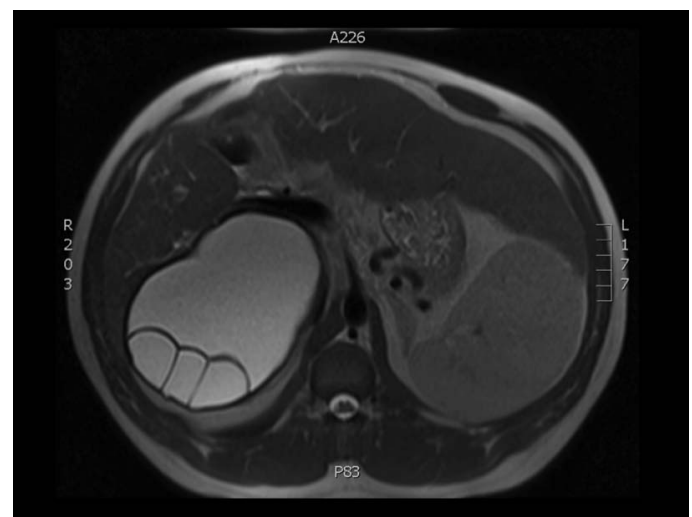

Figure 4 Magnetic resonance cholangiopancreatography: large right lobe hydatid cyst with daughter cysts posteriorly. There is communication between the cyst and the biliary tree indicated by mild primovist excretion into the cyst (not shown here). 


\section{Learning points}

- The larval form of Echinococcus granulosus is the cause of Echinococcal (hydatid) cysts commonly acquired from dogs that have been infected. ${ }^{2}$ It is very uncommon in the UK and USA. Patients are often asymptomatic and unaware. When symptoms present, they are usually because of the mass effect of an enlarging cyst, or complications such as intraperitoneal leakage, infection or biliary obstruction. Concomitant liver disease can accelerate the disease course. ${ }^{2}$

- Echinococcus granulosus cysts can rupture into the biliary tree and produce symptoms of biliary colic, obstructive jaundice, pancreatitis or cholangitis. Magnetic resonance cholangiopancreatography/ERCPs are sought in these patients before further management. ${ }^{2}$

- Surgery has been the traditional method to treat symptomatic hydatid cysts, although alternative approaches have replaced the treatment of choice in some patients such as puncture aspiration injection reaspiration. ${ }^{23} \mathrm{An}$ accelerated disease course due to hepatitis $B$ and $D$ coinfection, recurrent cholangitis and failure of previous surgical excision attempts lead to this patient to require a liver transplant.
In the following weeks, he presented multiple times to hospital with recurrent episodes of acute cholangitis secondary to hydatid cyst leak into the biliary tree. ${ }^{1}$ In view of this and his background, he was listed for a liver transplant, which he received 4 months later. An uneventful postoperative period and subsequent clinic follow-up showed no evidence of recurrent disease. He was continued on long-term albendazole and praziquantel.

Contributors MA gained consent from the patient, gathered the clinical information for the case and compiled the images. JP wrote the manuscript, performed a review of the literature and interpreted the content for learning points. JP and MA critically reviewed the article for intellectual content, were involved with the conception and design of the manuscript, and approved the version of the manuscript to be published.

Competing interests None declared.

Patient consent Obtained.

Provenance and peer review Not commissioned; externally peer reviewed.

\section{REFERENCES}

1 Tarcin 0 . Rupture of hydatid cyst into the biliary tract. Gastrointest Endosc 2006;63:325.

2 Junghanss T, da Silva AM, Horton J, et al. Clinical management of cystic echinococcosis: state of the art, problems, and perspectives. Am J Trop Med Hyg 2008;79:301-11.

3 Moro PL, Gilman RH, Verastegui M, et al. Human hydatidosis in the central Andes of Peru: evolution of the disease over 3 years. Clin Infect Dis 1999;29:807.

Copyright 2017 BMJ Publishing Group. All rights reserved. For permission to reuse any of this content visit http://group.bmj.com/group/rights-licensing/permissions.

BMJ Case Report Fellows may re-use this article for personal use and teaching without any further permission.

Become a Fellow of BMJ Case Reports today and you can:

- Submit as many cases as you like

- Enjoy fast sympathetic peer review and rapid publication of accepted articles

- Access all the published articles

- Re-use any of the published material for personal use and teaching without further permission

For information on Institutional Fellowships contact consortiasales@bmjgroup.com

Visit casereports.bmj.com for more articles like this and to become a Fellow 